\title{
Caesarean delivery and risk of childhood asthma development: meta-analysis
}

\author{
Agata Wypych-Ślusarska, Ewa Niewiadomska, Klaudia Oleksiuk, Karolina Krupa-Kotara, Joanna Głogowska-Ligus, \\ Jerzy Słowiński
}

Department of Epidemiology and Biostatistics, School of Health Sciences in Bytom, Medical University of Silesia in Katowice, Poland

Adv Dermatol Allergol 2021; XXXVIII (5): 819-826

DOI: https://doi.org/10.5114/ada.2020.96703

\begin{abstract}
Introduction: Several studies indicate that delivery by caesarean section may be one of the risk factors for the development of childhood asthma.

Aim: A meta-analysis was carried out to establish the relationship between delivery by caesarean section and asthma in children.

Material and methods: After a review of bibliographic databases, 41 articles were obtained and 12 of which were accepted for further analysis. The odds ratios (OR) included in the analysis were specified on the basis of data from the presented studies or were calculated using reported prevalence. The analysis took into account unadjusted OR. The heterogeneity of results was assessed using the $\chi^{2}$ test, determining $p<0.05$ as the level of significance. The analysis was performed using Statistica 13.3 and kit 4.0.67.

Results: Caesarean delivery was associated with an increased risk of development of childhood asthma $(O R=1.41)$; however, significant heterogeneity of results was demonstrated. A significantly higher risk of asthma was found in children born by caesarean section in the case where the disease was confirmed in a questionnaire-based study $(\mathrm{OR}=1.26,95 \% \mathrm{Cl}: 1.05-1.5)$, and the results of that study were homogeneous.

Conclusions: In the case of the diagnosis of asthma declared by parents in the questionnaire-based study, a significantly higher risk of disease occurrence was observed in children born by caesarean section. Due to the significant heterogeneity of the results of the studies, it cannot be clearly stated that caesarean delivery is a risk factor for the development of bronchial asthma.
\end{abstract}

Key words: asthma, caesarean delivery, childhood.

\section{Introduction}

Asthma is one of the most common chronic childhood diseases. The prevalence of the disease in Europe varies across countries. The data from 10 MeDALL (Mechanisms of the Development of ALLergy) cohorts indicate that, in the group of 4-year-old children, it ranged from $1.7 \%$ in Greece to $13.5 \%$ in England [1]. Asthma risk factors include indoor and outdoor environmental pollution, obesity, exposure to pet allergens, as well as prenatal risk factors [2]. Numerous studies also indicate a relationship between the type of delivery and the risk of bronchial asthma, although the results presented in them are inconclusive [3-7]. In the Copenhagen Prospective Studies on Asthma in Childhood 2000 (COPSAC $_{2000}$ ), delivery by caesarean section more than doubled the risk of bronchial asthma in children [8]. Follow-up observa- tions of children born in Scotland in 2007 also revealed that the planned caesarean section increases the risk of asthma [5]. There was no increase in risk in the event of an unscheduled caesarean delivery [5]. Moreover, a cohort study conducted in Germany did not show that the planned caesarean section increased the risk of bronchial asthma in children aged 15 years [7].

Given the growing number of deliveries by caesarean section and ambiguity of scientific evidence linking asthma and that type of delivery, this issue should continue to be the subject of research and discussion. According to OECD data, the rate of caesarean sections in 2016 was the lowest in Finland (162/1000 live births), Norway (162/1000 live births) and Sweden (177/1000 live births). The highest rates were recorded in Poland (385/1000 live births), Hungary (371/1000 live births) and

Address for correspondence: Agata Wypych-Ślusarska MD, Department of Epidemiology and Biostatistics, School of Health Sciences, Medical University of Silesia, 18 Piekarska St, 41-902 Bytom, Poland, phone: +48 501239 881, e-mail: awypych@sum.edu.pl Received: 3.04.2020, accepted: 19.05.2020. 
Italy (349/1000 live births) [9]. In some countries, an increase in the rate of caesarean sections was observed over the decade. By way of illustration, in Poland in 2006 it was 192/1000 live births and in Hungary 281/1000 live births [9].

\section{Aim}

In view of the cited data, a meta-analysis was planned to establish the relationship between the caesarean delivery and asthma in children.

\section{Material and methods}

Between May and June 2019, the bibliographic databases PubMed, Web of Science and Embase were reviewed. The same search criterion was applied to each database: caesarean section AND childhood asthma cohort study. The scope of the literature under review was limited to the period from January 2009 to June 2019. Another criterion pertained to whether the studies were carried out in European countries. The articles satisfying the adopted criteria were selected by three independent researchers. The full-text version of the works was then analysed by one author to establish their usefulness for the meta-analysis. The studies that were excluded: 1) focused on medical interventions applied before scheduled caesarean section to improve the functioning of the child's lungs, 2) described the methodology of the conducted research project, 3) were conference summaries, systematic reviews, letters to the editor or meta-analyses, 4) concerned other health issues related to caesarean section, and 5) were duplicates. In total, 41 articles were found and 29 of which were rejected. Finally, 12 publications were accepted for further analysis (Figure 1).
In the data synthesis, a random-effects model metaanalysis was used both for data as a whole and broken down by groups, taking into account the type of the conducted study to indicate participants with diagnosed asthma in the cohort (questionnaire, national registry of cases or hospital admissions). The odds ratios included in the analysis were specified on the basis of data from the presented studies or were calculated using reported prevalence. In the case where a study included adjusted and unadjusted ORs, unadjusted ORs were selected for analysis.

\section{Statistical analysis}

The forest plot was used to present the total odds ratio determined for all the data using the inverse variance-weighted method. The heterogeneity of results was assessed using $P^{2}$ index of inconsistency to indicate the percentage of variation across studies and the $\chi^{2}$ test, determining $p<0.05$ as the level of significance. The analysis was performed using Statistica 13.3 and kit 4.0.67, whereas the graphic presentation of the results was made in MS Excel 2013.

\section{Results}

The list of 12 cohorts selected for analysis is given in Appendix 1 [3-8, 10-15]. The studies were conducted from 1967 to 2012 in six European countries. Eleven presented groups took into account single births, while siblings were allowed in one of the cohorts. Only one study was based on the selection of twin pairs. Asthma cases were identified among the children subjected to examination, account being taken of annotations in the national registers of cases or hospital admissions (6 studies), diagnoses given by physicians designated for the purposes of the cohorts (3 studies), or the results of
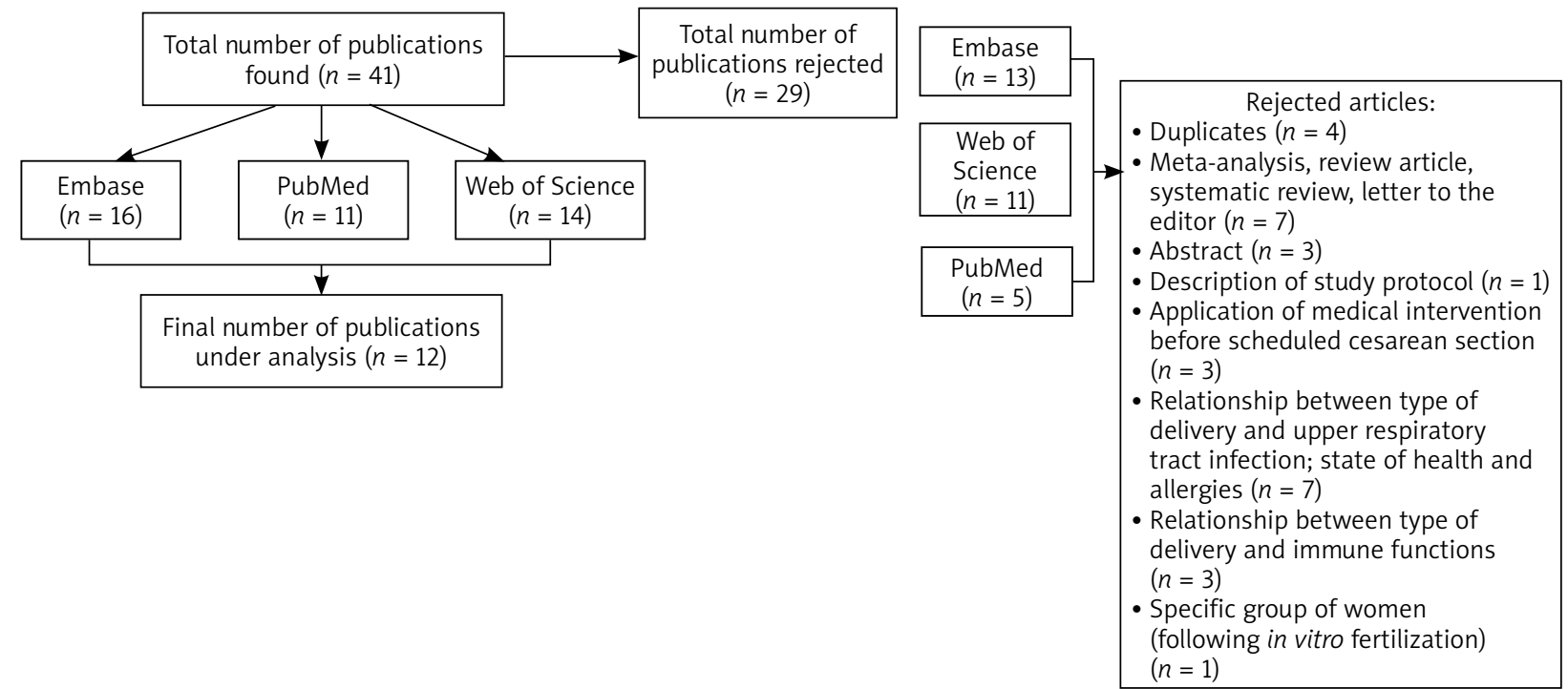

Figure 1. Publications search pattern 
questionnaire-based studies (3 studies). Table 1 shows details of the presented cohort studies.

Figure 2 presents individual and total ORs for delivery by caesarean section in relation to natural delivery. The presented forest chart is based on 12 cohort studies, taking into account the total number of 3,652,837 children, including 466,869 (12.8\%) delivered using invasive methods. According to the data, $0.4-9.3 \%$ of subjects developed asthma, whereas in the case of children born by caesarean section the percentage ranged from $0.8 \%$ to $12.1 \%$ of subjects delivered using an invasive method (Table 2). The total OR is 1.23 ( $95 \% \mathrm{Cl}: 0.97-1.58, p=0.09$ ), yet the results of the presented studies are significantly heterogeneous $(p<0.0001)$ with $l^{2}=99.29 \%(95 \% \mathrm{Cl}$ : 99.15-99.42\%).

Figures 3 and 4 show individual and total ORs for planned and unplanned delivery by caesarean section in relation to natural delivery. The presented forest charts are based on 7 cohort studies, taking into account the total number of 2,534,665 children, including 81,705 (3.2\%) born by planned caesarean delivery and 135,157 (5.3\%) by emergency caesarean delivery. In the case of children born by planned caesarean section, the percentage of diagnosed asthma ranged from $1.01 \%$ to $11.3 \%$ of subjects born using the planned invasive method (Table 2). The total OR is 1.36 (95\% Cl: $1.12-1.65, p=0.002)$, yet the results of the presented studies are significantly heterogeneous ( $p<0.0001)$ with $r^{2}=94.99 \%(95 \% \mathrm{Cl}$ : 92.39-96.71\%). In contrast, the percentage of children diagnosed with asthma among those born by emergency caesarean section ranged from $1.08 \%$ to $10.20 \%$. The results of the meta-analysis indicate that the risk of developing asthma is 1.41 times higher for children born by unplanned caesarean section in relation to natural delivery $(\mathrm{OR}=1.41,95 \% \mathrm{Cl}: 1.06-1.86)$. That analysis has likewise shown the significant heterogeneity of the results of the studies $(p<0.0001)$ with $R^{2}=97.25 \%(95 \% \mathrm{Cl}$ : 96.01-98.1\%).

Moreover, a meta-analysis was performed taking into account the type of study conducted to identify participants with diagnosed asthma in the cohort (Table 2). A significantly higher risk of asthma in children born by caesarean section was demonstrated when the disease was confirmed in the questionnaire-based study $(\mathrm{OR}=$ $1.26,95 \% \mathrm{Cl}: 1.05-1.5)$. Notably, the results of that study were homogeneous $(p=0.39)$.

\section{Discussion}

Bronchial asthma is one of the most common chronic diseases of childhood and its prevalence and course may depend on various risk factors, including those associated with the prenatal period. Observational studies suggest that the type of delivery may be one of the risk factors for the development of bronchial asthma in children, although such observations are not conclusive. A meta- analysis was therefore performed to analyse the relationship between delivery by caesarean section and the risk of asthma. Its findings showed that there is a greater risk of developing bronchial asthma in the case of caesarean delivery, both planned and unplanned, compared to natural delivery. This observation must nonetheless be interpreted with caution given the statistically significant heterogeneity of the results of the studies. This fact certainly does not discredit the conducted analyses in terms of either the method of selection of studies or the statistical methods used. Bronchial asthma involves a range of risk factors whose importance and participation in the pathomechanism of the disease are not completely clear. In view of the above, observational studies on the risk of the development of asthma in children born by caesarean section may be affected by numerous confounding factors. Properly planned cross-sectional studies (cohort studies) take into account possible confounding factors using adjusted OR or adjusted RR for statistical analyses. A similar situation occurred in the studies selected for analysis. The control concerned variously defined confounding factors. One study took into account age, education, socioeconomic status, while others also considered the mother's body mass index (BMI) and smoking. Consequently, only unadjusted ORs were included in the meta-analysis. Further, the studies subjected to analysis took into account different circumstances of the caesarean section in contrast to natural delivery, i.e. whether the caesarean section was planned or unplanned, or whether it was performed before and after the rupture of the membranes. Some observations compare caesarean delivery to natural delivery without any additional medical intervention, as well as with such intervention as the vacuum- or forceps-assisted vaginal delivery.

The meta-analysis of the results of the studies was conducted taking into account the risk of the development of bronchial asthma in the group of children born by caesarean section, both planned and unplanned, compared to natural childbirth. A similar risk of development of asthma was observed in children born by either unplanned or planned caesarean section, which is confirmed in other observations [5, 11]. In the Norwegian Mother and Child Cohort Study, the risk of development of asthma was similar for children delivered by acute and elective caesarean section, both for unadjusted and adjusted RR [11]. In the same way, no statistically significant differences in the risk of hospital admissions due to asthma were observed in the British cohort between children born by planned caesarean delivery and by unscheduled caesarean delivery [5]. In contrast, the Copenhagen Prospective Studies on Asthma in Childhood 2000 revealed a higher risk of development of asthma in children born by caesarean section before the rupture of the membranes than in children delivered by caesarean section after the rupture of the membranes [8]. In the aforementioned Copenhagen cohort, the time of caesarean 


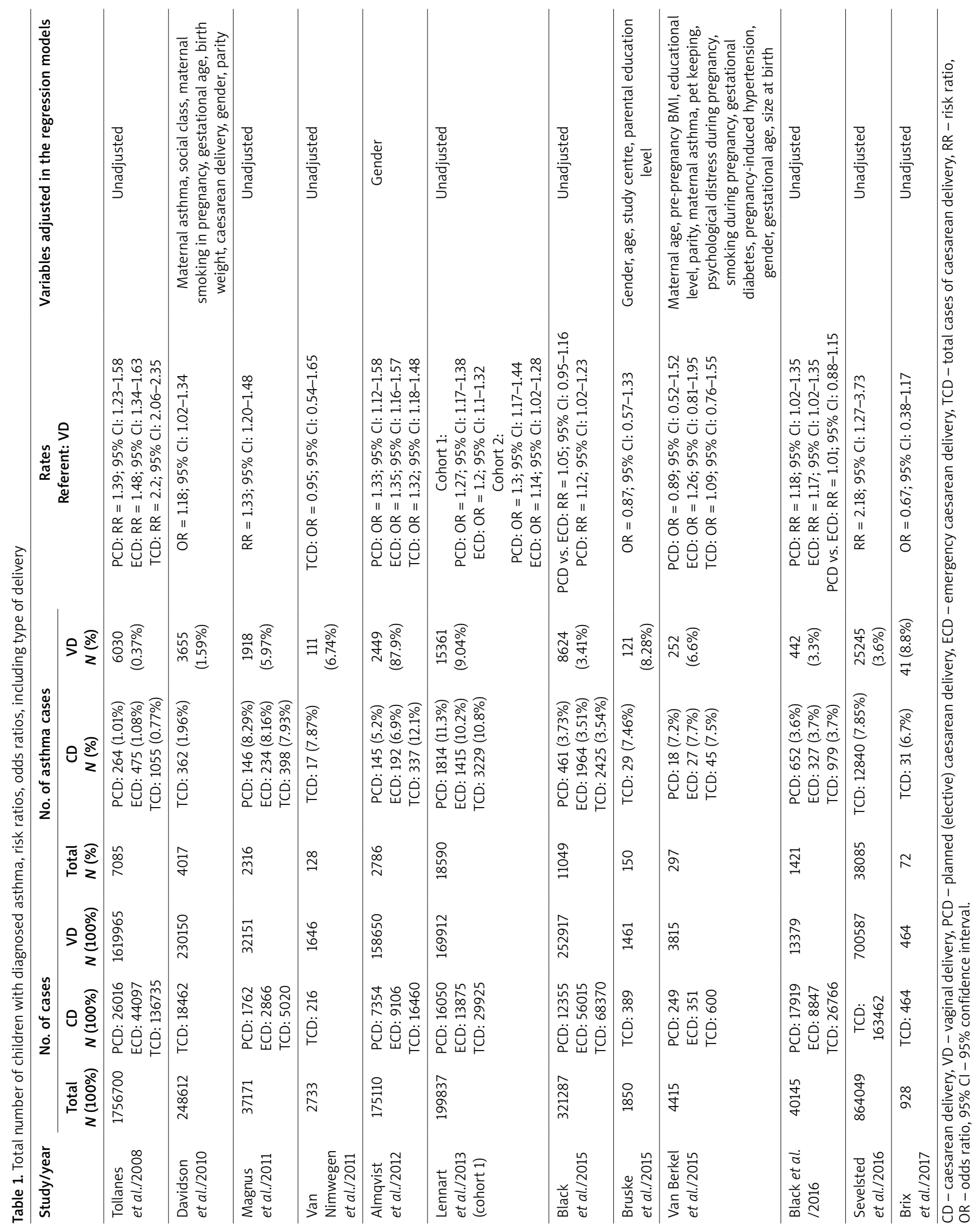


section itself was precisely determined. The other studies comparing planned and unplanned caesarean section to natural delivery did not specify exactly at what moment of the assisted childbirth the delivery occurred: before or after the rupture of the membranes.

The multiple risk factors for asthma and different definitions of delivery affect the possibility of comparing the particular results of observational studies and performing a meta-analysis. The best solution would be to include studies where the control concerns the same confounding factors and the caesarean section is defined in a uniform manner. However, in practice, it is impossible to control all the confounding factors and the adoption of such strict criteria for the inclusion of studies in the analysis would significantly limit their number and, as a result, effectively prevent the meta-analysis.

Our study did not make a distinction between delivery by caesarean section performed before and after the rupture of the membranes. Nevertheless, stringent criteria were applied to the selection of studies for further analysis. In addition to the current reports published in the last 10 years, our study focuses strictly on cohort studies conducted in Europe. The geographic limitation of the scope of the study appears to be extremely important in the context of asthma. Numerous studies point to the geographical differentiation in the prevalence of bronchial asthma [16-18]. In addition to the environmental factors such as temperature, humidity and landscape features, the socio-economic conditions may also be of considerable significance. Account should thus be taken of health care financing, state health policy, mother and child care and residents' preventive healthcare options and lifestyle. Given the large geographical diversity of the conducted studies, such key risk factors could distort the results of the analyses.

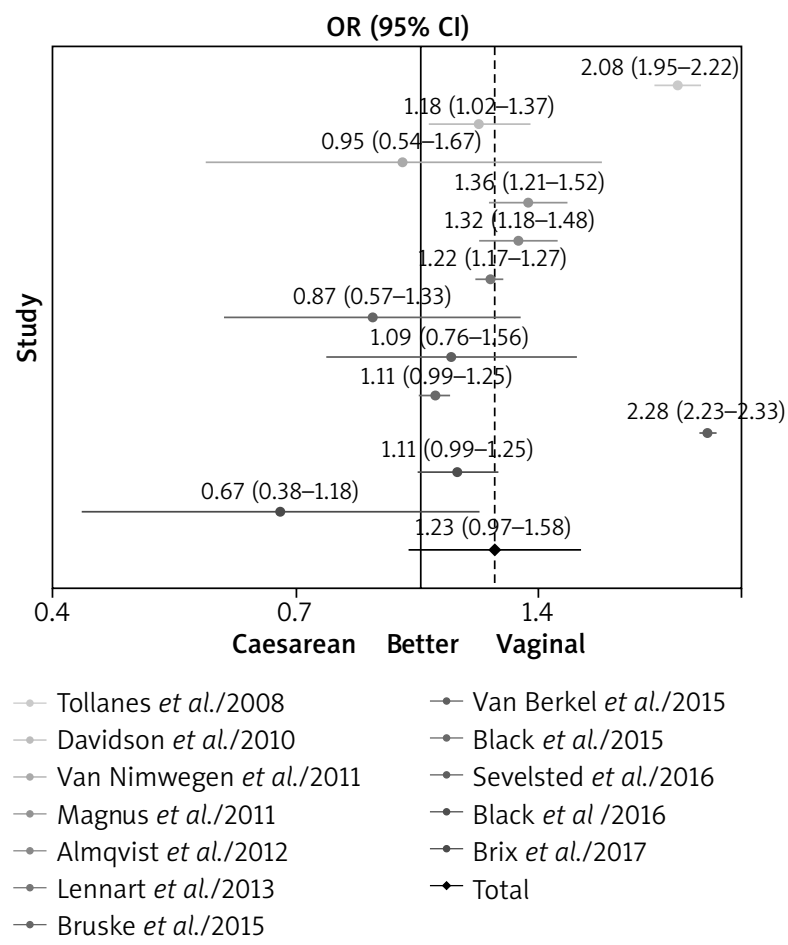

Figure 2. Relationship between the caesarean section and development of asthma expressed as OR along with the confidence interval $(95 \% \mathrm{Cl}$ - horizontal lines) on the basis of 12 European cohorts)

Table 2. Relationship between the caesarean section and development of asthma expressed as OR along with a 95\% confidence interval $(95 \% \mathrm{Cl})$ on the basis of 12 European cohorts taking into account the type of study determining the allocation to a group of participants with diagnosed asthma

\begin{tabular}{|c|c|c|c|c|c|c|}
\hline Study/year & Asthma & OR & $-95 \% \mathrm{Cl}$ & $+95 \% \mathrm{Cl}$ & $P$-value & Share \% \\
\hline Davidson et al./2010 & $\mathrm{R}$ & 1.18 & 1.02 & 1.37 & 0.03 & 12.76 \\
\hline Brix et al./2017 & $\mathrm{R}$ & 0.67 & 0.38 & 1.18 & 0.17 & 8.92 \\
\hline Almqvist et al./2012 & $\mathrm{R}$ & 1.32 & 1.18 & 1.48 & 0.00 & 12.92 \\
\hline Black et al./2015 & $\mathrm{R}$ & 1.04 & 0.99 & 1.09 & 0.08 & 13.12 \\
\hline Sevelsted et al./2016 & $\mathrm{R}$ & 2.28 & 2.23 & 2.33 & 0.00 & 13.15 \\
\hline Lennart et al./2013 & $\mathrm{R}$ & 1.22 & 1.17 & 1.27 & 0.00 & 13.13 \\
\hline Black et al. /2016 & $\mathrm{R}$ & 1.11 & 0.99 & 1.25 & 0.07 & 12.91 \\
\hline Tollanes et al./2008 & $\mathrm{R}$ & 2.08 & 1.95 & 2.22 & 0.00 & 13.08 \\
\hline Van Berkel et al./2015 & Q & 1.09 & 0.76 & 1.56 & 0.64 & 19.54 \\
\hline Magnus et al./2011 & Q & 1.36 & 1.21 & 1.52 & 0.00 & 71.46 \\
\hline Van Nimwegen et al./2011 & Q & 0.95 & 0.54 & 1.67 & 0.86 & 9.01 \\
\hline $\mathrm{R}$ - registry & & 1.31 & 0.97 & 1.77 & 0.08 & 100.00 \\
\hline Q - questionnaire & & 1.26 & 1.05 & 1.50 & 0.01 & 100.00 \\
\hline Total & & 1.27 & 1.09 & 1.48 & 0.00 & \\
\hline
\end{tabular}

$R$-asthma diagnosis in the national registry of cases or hospital admissions, $Q$ - note on asthma diagnosis confirmed in a questionnaire. 
OR $(95 \% \mathrm{Cl})$

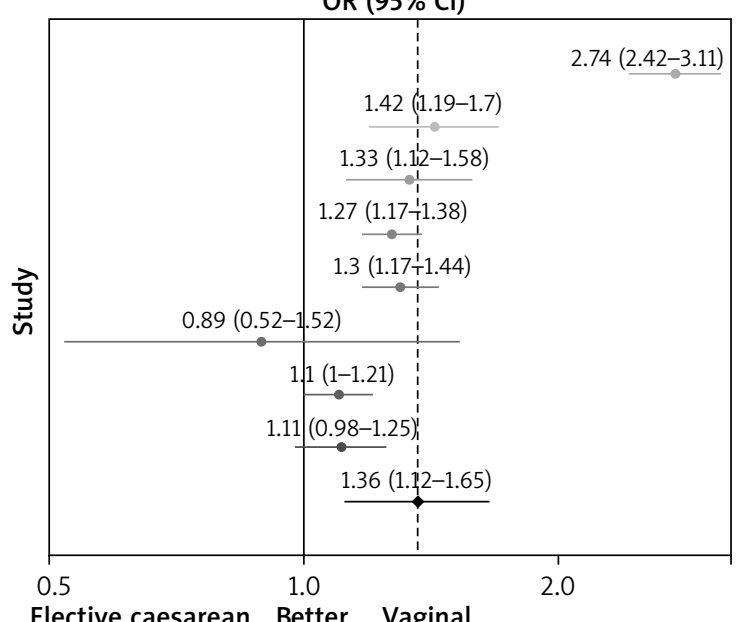

$\rightarrow-$ Tollanes et al./2008

$\rightarrow-$ Magnus et al./2011

- Almqvist et al./2012

- Lennart et al./2013 (cohort 1)

- Lennart et al./2013 (cohort 2)

Figure 3. Relationship between the planned (elective) caesarean section and development of asthma expressed as OR along with the $95 \%$ confidence interval $(95 \% \mathrm{Cl}-$ horizontal lines) on the basis of 6 European cohorts

In the selected studies, bronchial asthma was diagnosed at various stages of the child's development. In five studies, asthma was diagnosed in children over 10 years of age $[3,4,7,10,13]$, whereas in the remaining studies, the diagnoses were given earlier $[5,6,8,11,12$, $14,15]$, including 2 cases where asthma was diagnosed in the first years of life $[11,14]$. The age at which the disease was first diagnosed is crucial for further analysis. Diagnosis of asthma in the first years of life seems to be somewhat problematic. Wheezing or dyspnoea occurring in the first years of life may not always imply the subsequent development of bronchial asthma [7]. Some authors indicate that the diagnosis made before a child reaches the age of 6 is often based solely on the symptoms of the disease, since it is not always possible to perform pulmonary function tests [19].

Another factor related to the diagnosis of asthma that may underlie the heterogeneity of the study results is the method of diagnosis. In most European countries where cohort studies were conducted, the diagnosis of the disease can be given by the GP. The availability and possibility of using all diagnostic methods has an impact on the prevalence of childhood asthma in a given region. For instance, in the Netherlands, lung function tests are not typically performed by the GP. In the case of every 5th child, the diagnosis was made on the basis of symptoms, which may often lead to overdiagnosis [19].

The meta-analysis also took into account the type of study conducted to identify participants with asthma in

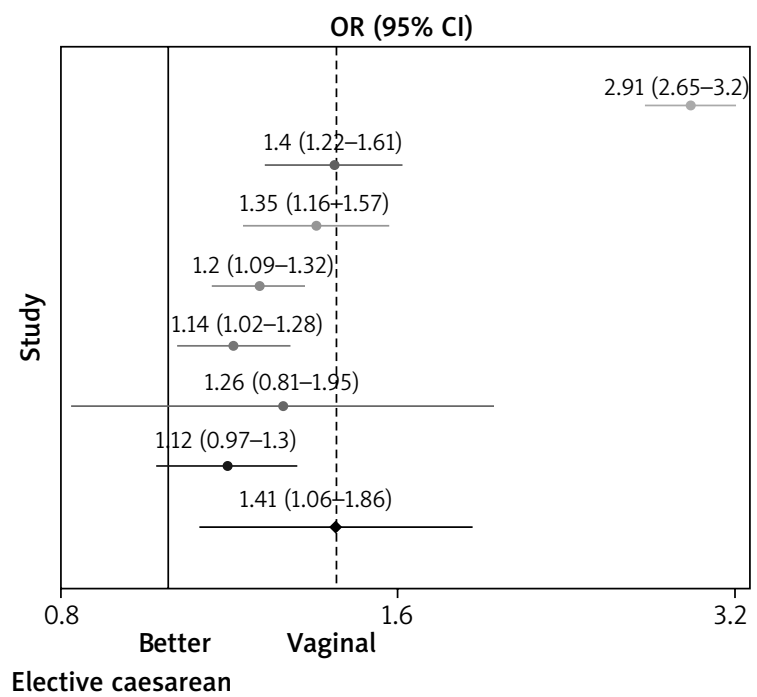

$$
\begin{array}{ll}
\rightarrow-\text { Tollanes et al./2008 } & - \text { - Lennart et al./2013 (cohort 2) } \\
\text { - - Magnus et al./2011 } & - \text { - Van Berkel et al./2015 } \\
\text { - - Almqvist et al./2012 } & - \text { - Black et al /2016 } \\
\text { - - Lennart et al./2013 (cohort 1) } & - \text { - Total }
\end{array}
$$

Figure 4. Relationship between emergency caesarean section and development of asthma expressed as OR along with the $95 \%$ confidence interval (95\% Cl - horizontal lines) on the basis of 6 European cohorts

the cohort. A significantly higher risk of asthma in children delivered by caesarean section was demonstrated when the disease was confirmed in a questionnairebased study and the results of that study were homogeneous. The questionnaire in this case appears to be a reliable source of information on the diagnosis reached by the doctor. As given above, the data obtained from the registers may contain information on the diagnosis of the disease made both by the GP and specialist doctors who have various diagnostic options at their disposal. Moreover, registry-based studies often contain information on the use of anti-asthma medicines which may also be prescribed in the case where symptoms of the disease occur. It cannot therefore be ruled out that a meta-analysis based on asthma diagnosed by the physician and reported in the questionnaire would entail the homogeneity of the results of the study.

Potential limitations of this meta-analysis are associated mostly with a small number of cohort studies conducted in Europe, relating to the association between caesarean delivery and the risk of childhood asthma development. The methodology applied in these studies and the number of investigated children show a strong heterogeneity, what can affect the results of meta-analysis. Studies with a larger number of cases could play a greater role in the final statistical analysis, compared to studies with a smaller number of cases. Due to high heterogeneity a random effect model was applied in the analysis, with suitable weights assigned to the studies. 
However, the index of inconsistency calculated for needs of particular analyses showed significant variability, ranging from 95\% to $99.3 \%$. This may result from the choice of unadjusted ORs, which was related with modelling techniques assumed in particular studies. Furthermore, the method of conducting the study is an important criterion. Therefore, authors decided to perform a stratified analysis due to the type of study determining the allocation to a group of participants with diagnosed asthma (registry/questionnaire). The results of this analysis turned to be homogeneous.

\section{Conclusions}

Based on the conducted analyses, it cannot be clearly stated whether delivery by caesarean section constitutes a risk factor for the development of bronchial asthma in children. The results of the studies were marked by significant heterogeneity. In contrast, in the case of the diagnosis of asthma declared by parents in the questionnaire-based study, a significantly higher risk of disease occurrence was observed in children born by caesarean section. In order to obtain consistent conclusions, it is recommended that the search criteria for studies as regards the method of obtaining information on the disease should be narrowed.

\section{Conflict of interest}

The authors declare no conflict of interest.

\section{References}

1. Uphoff EP, Bird PK, Anto JM, et al. Variations in the prevalence of childhood asthma and wheeze in MeDALL cohorts in Europe. ERJ Open Res 2017; 3: 00150-2016 [https://doi. org/10.1183/23120541.00150-2016].

2. Baseley R, Semprini A, Mitchell EA. Risk factors for asthma: is prevention possible? Lancet 2015; 386: 1075-85.

3. Brix N, Stokholm L, Jonsdottir F, et al. Comparable risk of childhood asthma after vaginal delivery and emergency caesarean section. Dan Med J 2016; 64: A5313.

4. Davidson R, Roberts SE, Wotton CJ, et al. Influence of maternal and perinatal factors on subsequent hospitalization for asthma in children: evidence from the Oxford record linkage study. BMC Pulm Med 2010; 10: 14.

5. Black M, Bhattacharya S, Philip S, et al. Planned cesarean delivery at term and adverse outcomes in childhood health. JAMA 2015; 314: 2271-9.

6. Black M, Bhattacharya S, Philip S, et al. Planned cesarean delivery at term and adverse outcomes in childhood health: a record - linkage study. PLoS Med 2016; 13: e1001973.

7. Bruske I, Pei Z, Thiering E, et al. Caesarean section has no impact on lung function at the age of 15 years. Pediatr Pulmonol 2015; 50: 1262-9.

8. Sevelsted A, Stokholm J, Bisgaard H. Risk of asthma from cesarean delivery depends on membrane rupture. J Pediatr 2016; 171: 38-42.
9. OECD (2020). "Caesarean sections” (indicator), https://doi. org/10.1787/adc3c39f-en (accessed on 02 April 2020).

10. Tollånes MC, Moster D, Daltveit AK, et al. Cesarean section and risk of severe childhood asthma: a population-based cohort study. J Pediatr 2018; 153: 112-6.

11. Magnus MC, Håberg SE, Stigum H, et al. Delivery by cesarean section and early childhood respiratory symptoms and disorders. the norwegian mother and child cohort study. Am J Epidemiol 2011; 174: 1275-85.

12. van Nimwegen FA, Penders J, Stobberingh EE, et al. Mode and place of delivery, gastrointestinal microbiota, and their influence on asthma and atopy. J Allergy Clin Immunol 2011; 128: 948-55.

13. Almqvist C, Cnattingius S, Lichtenstein P, et al. The impact of birth mode of delivery on childhood asthma and allergic diseases - a sibling study. Clin Exp Allergy 2012; 42: 1369-76.

14. Bråbäck L, Ekéus C, Lowe AJ, et al. Confounding with familial determinants affects the association between mode of delivery and childhood asthma medication - a national cohort study. Allergy Asthma Clin Immunol 2013; 9: 14.

15. van Berkel AC, den Dekker HT, Jaddoe VW, et al. Mode of delivery and childhood fractional exhaled nitric oxide, interrupter resistance and asthma: the Generation R study. Pediatr Allergy Immunol 2015; 26: 330-6.

16. Soriano JB, Abajobir AA, Abate KH, et. al. Global, regional, and national deaths, prevalence, disability-adjusted life years, and years lived with disability for chronic obstructive pulmonary disease and asthma, 1990-2015: a systematic analysis for the Global Burden of Disease Study 2015. Lancet Respir Med 2017; 5: 691-706.

17. Pearce N, Sunyer J, Cheng S, et al. Comparison of asthma prevalence in the ISAAC and the ECRHS. ISAAC Steering Committee and the European Community Respiratory Health Survey. International Study of Asthma and Allergies in Childhood. Eur Respir J 2000; 16: 420-6.

18. Global Initiative for Asthma. Global Strategy for Asthma Management and Prevention, 2019. www.ginasthma.org.

19. van den Akker IL, van Lujin K, Verheij T. Overdiagnosis of asthma in children in primary care: a retrospective analysis. Br J Gen Pract 2016; 66: e152-7. 


\section{Appendix}

Appendix 1. Cohort studies shown in publications in 2008-2017

\begin{tabular}{|c|c|c|c|c|c|c|}
\hline Study & Year & Country & Period & Birth & Register of asthma & $\begin{array}{l}\text { Age of asthma } \\
\text { diagnosis }\end{array}$ \\
\hline $\begin{array}{l}\text { Tollanes } \\
\text { et al. [10] }\end{array}$ & 2008 & Norway & 1967-1998 & Single & $\begin{array}{c}\text { The Norwegian National Insurance } \\
\text { Scheme (NIS) }\end{array}$ & $<18$ years old \\
\hline $\begin{array}{l}\text { Davidson } \\
\text { et al. [4] }\end{array}$ & 2010 & UK - England & 1970-1989 & Single & $\begin{array}{l}\text { Registry of Hospital admission or } \\
\text { hospital-based day care for asthma } \\
\text { (ORLS) }\end{array}$ & $<18$ years old \\
\hline $\begin{array}{l}\text { Magnus } \\
\text { et al. [11] }\end{array}$ & 2011 & Norway & $2001-2007$ & Single & Questionnaire & $<3$ years old \\
\hline $\begin{array}{l}\text { Van Nimwegen } \\
\text { et al. [12] }\end{array}$ & 2011 & Netherlands & $2000-2003$ & Single & $\begin{array}{l}\text { Questionnaires in the International } \\
\text { Study on Asthma and Allergy in } \\
\text { Childhood (ISAAC) }\end{array}$ & $6-7$ years old \\
\hline $\begin{array}{l}\text { Almqvist } \\
\text { et al. [13] }\end{array}$ & 2012 & Sweden & 1993-1999 & Siblings & The National Patient Register (NPR) & $\begin{array}{l}13 \text { years old } \\
\text { Asthma diagnosis during } \\
\text { follow-up year }\end{array}$ \\
\hline $\begin{array}{l}\text { Braback } \\
\text { et al. [14] }\end{array}$ & 2013 & Sweden & 1999-2006 & Single & $\begin{array}{l}\text { The Swedish National Board of Health } \\
\text { and Welfare and Statistics, Sweden }\end{array}$ & $\begin{array}{l}\text { Cohort 1: } 2-5 \text { years old } \\
\text { Cohort 2: 6-9 years old }\end{array}$ \\
\hline Black et al. [5] & 2015 & UK - Scotland & 1993-2007 & Single & $\begin{array}{l}\text { The Scottish Morbidity Record SMR02 } \\
\text { and SMR01 }\end{array}$ & 6 years old \\
\hline Bruske et al. [7] & 2015 & Germany & 1995-1998 & Single & Spirometry tests, doctor diagnoses & 15 years old \\
\hline $\begin{array}{l}\text { Van Berkel } \\
\text { et al. [15] }\end{array}$ & 2015 & Netherlands & $2002-2006$ & Single & $\begin{array}{c}\text { Questionnaires in the International } \\
\text { Study on Asthma and Allergy in } \\
\text { Childhood (ISAAC) }\end{array}$ & 6 years old \\
\hline Black et al. [6] & 2016 & UK - Scotland & 1993-2007 & Single & $\begin{array}{l}\text { The Scottish Morbidity Record SMR02 } \\
\text { and SMR01 }\end{array}$ & 6 years old \\
\hline $\begin{array}{l}\text { Sevelsted } \\
\text { et al. [8] }\end{array}$ & 2016 & Denmark & $1998-2010$ & Single & $\begin{array}{c}\text { The National Prescription Registry and } \\
\text { the Danish National Patient Registry }\end{array}$ & $<7$ years old \\
\hline Brix et al. [3] & 2017 & Denmark & 1997-2012 & Twins & The Danish National Patient Registry & 15 years old \\
\hline
\end{tabular}

